\title{
Analysis of Short Circuit Fault for 4.6GHz/6MW LHCD High Voltage Power Supply
}

\author{
Zhigang Yang ${ }^{1,2}$, Peng Fu ${ }^{1,2}$, Fei Guo ${ }^{1}$, Haozhang Sun ${ }^{1}$, Jian Zhang ${ }^{1}$, Mao Wang ${ }^{1}$, Fukun Liu ${ }^{1}$,
}

${ }^{1}$ Department of Power Supply and Control Engineering, Institute of Plasma Physics, Chinese Academy of Sciences, Hefei, China

${ }^{2}$ Science Island Branch of Graduate School, University of Science and Technology of China, Hefei, China

\section{Email address:}

yangzhigang@ipp.ac.cn (Zhigang Yang), yyhuang@ipp.ac.cn (Yiyun Huang)

${ }^{*}$ Corresponding author

\section{To cite this article:}

Zhigang Yang, Peng Fu, Fei Guo, Haozhang Sun, Jian Zhang, Mao Wang, Fukun Liu, Yiyun Huang. Analysis of Short Circuit Fault for 4.6GHz/6MW LHCD High Voltage Power Supply. Journal of Electrical and Electronic Engineering. Vol. 5, No. 4, 2017, pp. 116-122. doi: $10.11648 /$ j.jeee.20170504.12

Received: May 25, 2017; Accepted: June 3, 2017; Published: July 17, 2017

\begin{abstract}
GHz} / 6 \mathrm{MW}$ Lower Hybrid Current Drive (LHCD) is one of plasma current heating methods for Experimental Advanced Superconducting Tokamak (EAST). High Voltage Power Supply (HVPS) is the power supply subsystem of 4.6GHz/6MW LHCD system, which was designed, built and accepted successfully by Chinese National Development and Reform Commission in 2015. Then the new system has been in use for the 2015 EAST campaign. This paper presents the structure of 4.6GHz/6MW LHCD-HVPS and its transient operation state when its klystron load has short circuit fault. In order to protect the klystron and HVPS itself, the short-circuit fault and its transient process are analyzed and calculated in detail. And a three-electrode gas switch has been built to eliminate the short-circuit fault in microseconds. In addition, the effectiveness of the three-electrode gas switch has been verified by simulation and experiment result. The HVPS has been used in $4.6 \mathrm{GHz} / 6 \mathrm{MW}$ LHCD system and it has good performance for the entire 2015 EAST campaign.
\end{abstract}

Keywords: Lower Hybrid Current Drive, High Voltage Power Supply, Pulse Step Modulation, Three-Electrode Gas Switch, Short Circuit Fault

\section{Introduction}

The Experimental Advanced Superconducting Tokamak (EAST) [1] is the first non-circular section and fully superconducting tokamak. Which was built in 2006 and has done series physical experiments. In order to achieve steady state and high performance plasma current, a new lower hybrid current drive (LHCD) [2], [3], [4] system at a frequency of $4.6 \mathrm{GHz}$ with $6 \mathrm{MW}$ power has been built in 2014 and been accepted successfully by Chinese National Development and Reform Commission in 2015. In order to satisfy the property of Lower Hybrid Wave (LHW) [5], [6] from 4.6GHz LHCD, the 4.6GHz/6MW LHCD High Voltage Power Supply (HVPS) based on Pulse Step Modulation (PSM) switching technology [7], [8], [9] has been built in the meantime.

As klystron loads are under the condition of strong electric field during the EAST campaign. The klystron loads may happen short-circuit fault occasionally. In order to avoid damage the klystron loads and HVPS itself, the power energy absorbed by one klystron must be no more than 10J [10], [11] from start of short-circuit fault to action of protection switch. However, the transient process of short-circuit fault is few studied during LHCD- HVPS operation.

In this paper, the $4.6 \mathrm{GHz} / 6 \mathrm{MW}$ LHCD-HVPS is mainly introduced, and the transient process of short-circuit fault is analyzed and calculated in detail, including the transient energy of distribution capacitance and stray inductance of high voltage transmission line, the remaining energy of HVPS. Then a three-electrode gas switch has been presented for protecting the klystron and HVPS against short-circuit fault. In the end, the experimental results with $4.6 \mathrm{GHz} / 6 \mathrm{MW}$ LHCD system is presented in 2015 EAST campaign, demonstrating the capability of system. 


\section{Description of HVPS System}

Totally there are four same sets of HVPS system for $4.6 \mathrm{GHz} / 6 \mathrm{MW}$ LHCD system and the main circuit configuration of one set of HVPS system is shown in Figure1. Each HVPS system is composed of $10 \mathrm{kV}$ power distribution cabinet, soft start switchgear, multi-windings isolation transformer, PSM module power supply, control units, and so on. Three phase 10kVAC net supplies 2 multi-windings isolation rectifier transformers through the power distribution cabinet and the soft start switchgear. Then 64 identical PSM modules in series connection are made up a DC power supply system. The output voltage of each module power supply is 810VDC. Different kinds of output voltage waveform can be gotten by controlling the IGBT of each PSM module power supply. Therefore, the maximum output voltage of the HVPS system is about $-50 \mathrm{kV}$. Then it serves for 6 klystrons in parallel. The main parameters of each HVPS system are listed in Table 1.

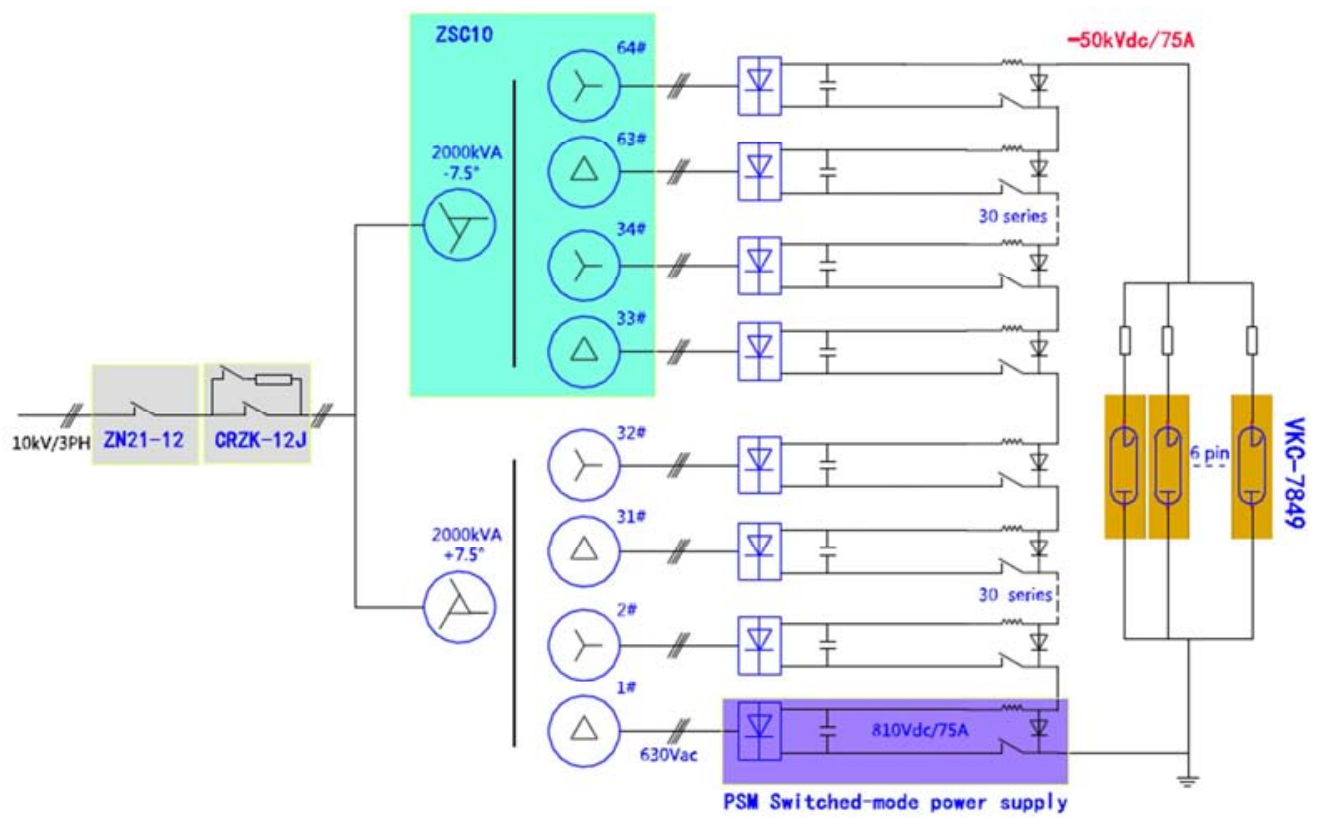

Figure 1. The main circuit configuration of one set HVPS for 4.6GHz LHCD system.

Table 1. The main parameters of one set HVPS system.

\begin{tabular}{ll}
\hline Item & Parameter \\
\hline System Name & $4.6 \mathrm{GHz}$ LHCD-HVPS \\
Rated Voltage & $50 \mathrm{kVDC}$ \\
Rated Current & $75 \mathrm{~A}$ \\
Efficiency & $40 \%$ \\
Pulse Width & $0-1000 \mathrm{~S}$ \\
Stability & $1 \%$ \\
Precision & $1 \%$ \\
Response Speed & $1 \mathrm{mS}$ \\
\hline
\end{tabular}

\section{Transient Process Analysis of Short-Circuit Fault}

When the klystron happens the short-circuit fault, the protection switch will act soon. During the transient process, there are mainly three parts of energy injecting into the klystron, including the energy of distribution capacitance, the energy of stray inductance and the remaining energy of HVPS. The detailed analysis is presented respectively as below.

\subsection{The Distribution Capacitance}

The klystron is a special high-power pulse load, which needs wide range of voltage regulation, fast response time and frequent anti-short circuit ability. So the transmission cables between HVPS and klystron must have the special design requirements, including transmitting $1.5 \mathrm{MW}$ power from HVPS to klystron, anti-electromagnetic interference and as far as possible small distribution capacitance.

As shown in Figure2. it is the circuit topology of HVPS, klystron and the transmission cables. $S$ is a three-electrode gas switch. $F_{u}$ is a copper fuse. $L$ is the transmission cables. $R_{L}$ is the current limiting resistor. $K$ is the klystron. One end of a $25 \mathrm{~mm}^{2}$ XLPE cable with $30 \mathrm{~m}$ length is connected the high voltage terminal of HVPS. The other end is connected 6 klystrons in parallel by $6 \mathrm{~mm}^{2}$ XLPE cable. Every $6 \mathrm{~mm}^{2}$ XLPE cable is $80 \mathrm{~m}$ length. Finally, the other joint is connected to the ground through a $50 \mathrm{~mm}^{2}$ XLPE cable with $100 \mathrm{~m}$ length. Obviously, there will be some distribution capacitances between different cables under the high electric field.

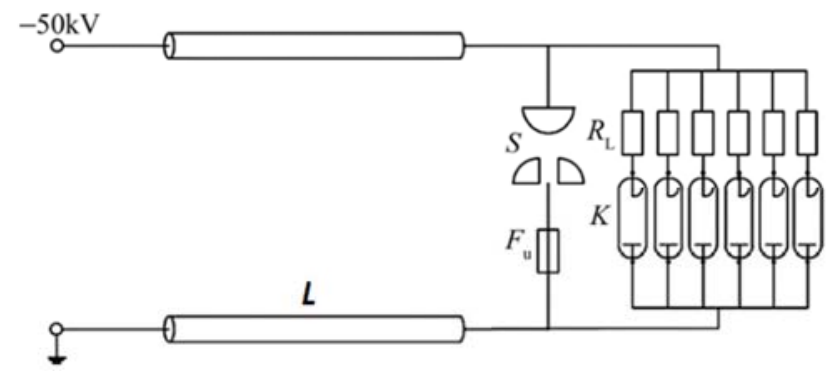

Figure 2. The circuit topology of HVPS with loads. 
The electric axis method [12] will be used to calculate the distribution capacitance between different cables in this chapter. Build a distribution capacitance model between two parallel cables as shown in Figure3.

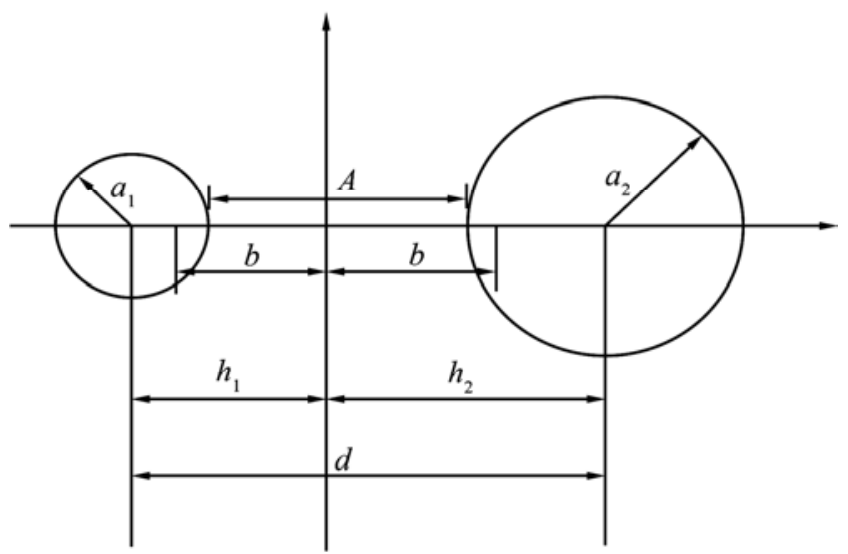

Figure 3. A distribution capacitance model between two parallel cables.

From Figure 3., list a equation as below.

$$
\left\{\begin{array}{l}
h_{1}^{2}-h_{2}^{2}=a_{1}^{2}-a_{2}^{2} \\
h_{1}+h_{2}=d
\end{array}\right.
$$

$a_{1}, a_{2}$ is the radius of cable, $b$ is the length between the origin and cable conductor, $h_{1}, h_{2}$ is the length between the origin and cable center, $d$ is the length between different cables center.

According to equation (1),

$$
\begin{gathered}
\left\{\begin{array}{l}
h_{1}=\frac{d^{2}+a_{1}^{2}-a_{2}^{2}}{2 d} \\
h_{2}=\frac{d^{2}-a_{1}^{2}+a_{2}^{2}}{2 d}
\end{array}\right. \\
b=\sqrt{\left(\frac{d^{2}+a_{1}^{2}-a_{2}^{2}}{2 d}\right)^{2}-a_{1}^{2}}=\sqrt{\left(\frac{d^{2}-a_{1}^{2}+a_{2}^{2}}{2 d}\right)^{2}-a_{2}^{2}}
\end{gathered}
$$

Then according to the electric axis method, the electric potential of two cables $\psi_{1}, \psi_{2}$ are,

$$
\left\{\begin{array}{l}
\phi_{1}=\frac{q}{2 \pi \varepsilon_{0}} \ln \frac{b+\left(h_{2}-a_{2}\right)}{b-\left(h_{2}-a_{2}\right)} \\
\phi_{2}=\frac{q}{2 \pi \varepsilon_{0}} \ln \frac{b-\left(h_{1}-a_{1}\right)}{b+\left(h_{1}-a_{1}\right)}
\end{array}\right.
$$

The electric potential difference between two cables is,

$$
U=\phi_{1}-\phi_{2}=\frac{q}{2 \pi \varepsilon_{0}} \ln \left[\frac{b+\left(h_{2}-a_{2}\right)}{b-\left(h_{2}-a_{2}\right)} \times \frac{b+\left(h_{1}-a_{1}\right)}{b-\left(h_{1}-a_{1}\right)}\right]
$$

The distribution capacitance of one metre cable between two cables is,

$$
C_{\mathrm{o}}^{\prime}=\frac{q}{U}=\frac{2 \pi \varepsilon_{0}}{\ln \left[\frac{b+\left(h_{2}-a_{2}\right)}{b-\left(h_{2}-a_{2}\right)} \times \frac{b+\left(h_{1}-a_{1}\right)}{b-\left(h_{1}-a_{1}\right)}\right]}
$$

In the HVPS, $a_{1}=8.28 \mathrm{~mm}$ for the $50 \mathrm{~mm}^{2}$ cable, $a_{2}=13.25 \mathrm{~mm}$ for the $25 \mathrm{~mm}^{2}$ cable, $a_{2}=10.5 \mathrm{~mm}$ for the $6 \mathrm{~mm}^{2}$ cable. According to equation (6), the distribution capacitance of one metre cable between $50 \mathrm{~mm}^{2}$ cable and $25 \mathrm{~mm}^{2}$ is $C_{\mathrm{o} 1}^{\prime}=8.21 \mathrm{pF}$, the distribution capacitance of one metre cable between $50 \mathrm{~mm}^{2}$ cable and $6 \mathrm{~mm}^{2}$ is $C_{\mathrm{o} 2}^{\prime}=8.02 \mathrm{pF}$.

So the total distribution capacitance of HVPS cables is,

$$
C_{\mathrm{o}}=30 \times 8.21+80 \times 8.02 \approx 888 \mathrm{pF}=0.888 \mathrm{nF}
$$

\subsection{The Stray Inductance}

HVPS needs response in microseconds and overshoot less than $1 \%$ for the klystron load. The stray inductance affects the response rate of HVPS. So it is necessary to analyze the stray inductance and calculate the energy of stray inductance between HVPS and the klystron.

The stray inductance of one metre transmission cable is,

$$
L=\frac{\mu \ln R_{2} / R_{1}}{2 \pi}
$$

$R_{1}$ is the radius of inner conductor, $R_{2}$ is the radius of outer conductor, $\mu$ is the magnetic conductivity, $\mu=4 \pi \times 10^{-7}$ for XLPE.

According to equation (8),

The stray inductance of one metre $25 \mathrm{~mm}^{2}$ transmission cable is $L_{1}=0.309 \mu \mathrm{H}$.

The stray inductance of one metre $6 \mathrm{~mm}^{2}$ transmission cable is $L_{2}=0.406 \mu \mathrm{H}$.

The stray inductance of one metre $50 \mathrm{~mm}^{2}$ transmission cable is $L_{3}=0.146 \mu \mathrm{H}$.

So, the total stray inductance of one loop is,

$$
L_{o}=30 * L_{1}+80 * L_{2}+110 * L_{3}=57.81 \mu \mathrm{H}
$$

\subsection{The Analytic Calculation}

The protection stage of short circuit fault is the key transient process for HVPS. When the klystron occurs short circuit fault, the protection transient process will include two stages. One stage is from the starting of short circuit fault to the action of the three-electrode gas switch. The other stage is from the action of the three-electrode gas switch to the ending of protection. During the protection transient process, the change curve sketch of current is shown in Figure4. When the klystron occurs short circuit fault at $t_{1}$, the current increases from rated current $I_{0}$. To reach the set value of overcurrent protection $I_{s}$ at $t_{2}$. At the moment, the three-electrode gas switch is triggered, and operates at $t_{3}$. The klystron is protected. $I$ reaches to the max point $I_{h}$. The distribution capacitance and the stray inductance start to discharge, and the current decreases. It changes to zero at $t_{4}$ eventually. 


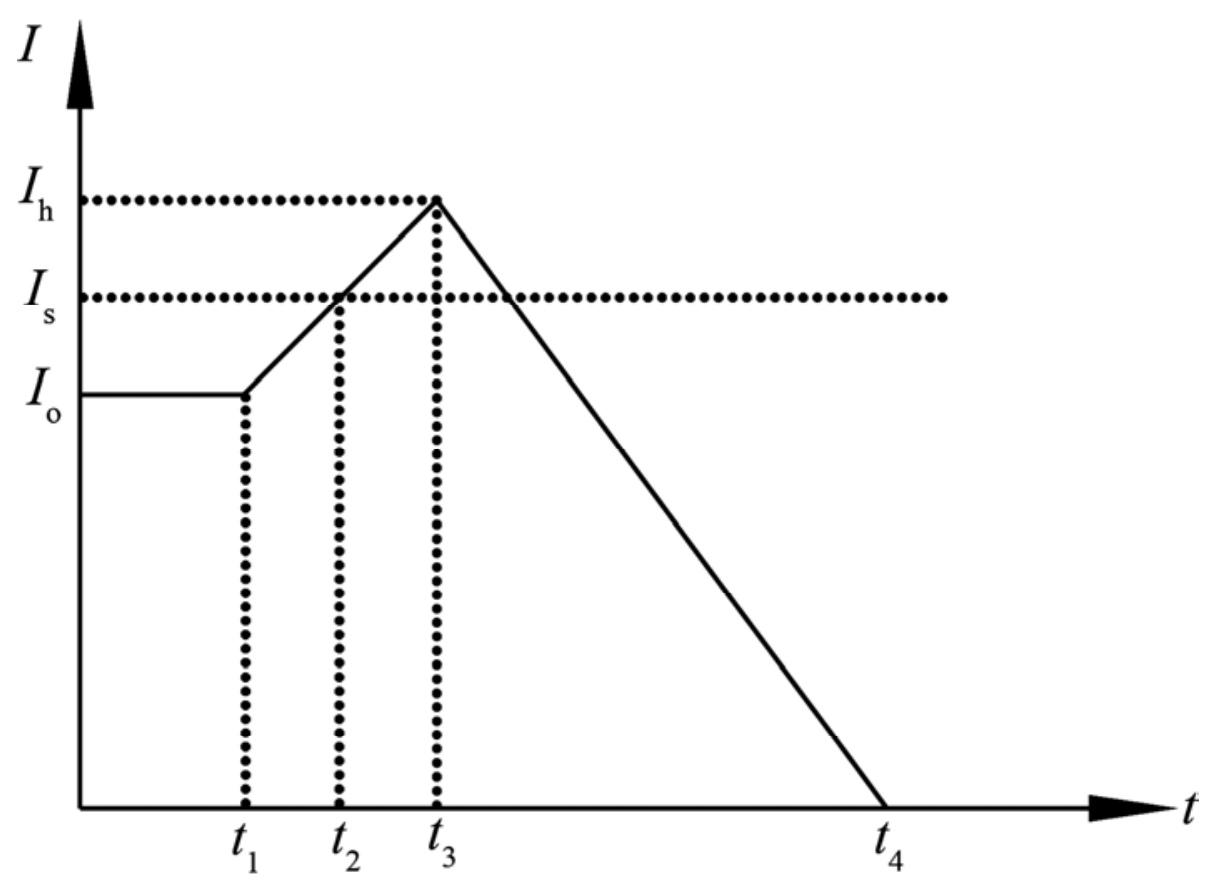

Figure 4. The change curve sketch of current.

Here, a RLC equivalent model with second order network has been built, as shown in Figure 5.

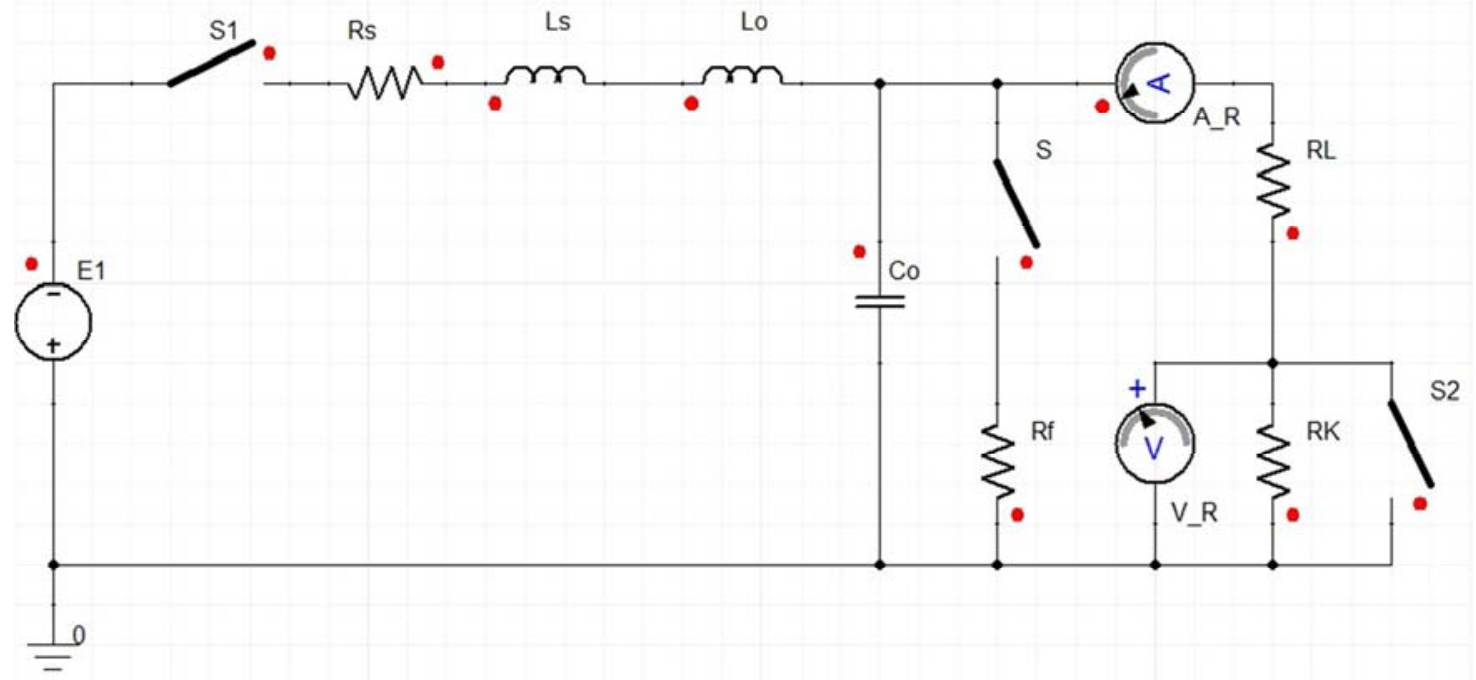

Figure 5. RLC equivalent model with second order network.

$E_{l}$ is the power source, and $E_{l}=-50 \mathrm{kV} . R_{s}$ is the internal resistance of power source, and $R_{s}=1 \Omega$. $L_{s}$ is the current limiting inductor, and $=13.6 \mathrm{mH}$. $R_{L}$ is the current limiting resistor, and $R_{L}=30 \Omega . R_{K}$ is the resistance of a klystron, and $R_{K}=700 \Omega$. $S_{1}$ is the main switch model. $S$ is the model of the three-electrode gas switch. $R_{f}$ is the fuse. $S_{2}$ is the switch model of short circuit fault. $L_{o}$ is the stray inductance. $C_{o}$ is the distribution capacitance.

When $S_{l}$ is closed, the equivalent circuit becomes a second order system with a series damping and a parallel damping [13]. The transfer function between $E_{l}$ and $V_{-} R$ is,

$$
\begin{aligned}
& \frac{U_{\mathrm{o}}(s)}{U_{\mathrm{i}}(s)}=\frac{\frac{\left(R_{\mathrm{L}}+R_{\mathrm{K}}\right) / s C_{\mathrm{o}}}{R_{\mathrm{L}}+R_{\mathrm{K}}+1 / s C_{\mathrm{o}}}}{R_{\mathrm{S}}+s\left(L_{\mathrm{S}}+L_{\mathrm{o}}\right)+\frac{\left(R_{\mathrm{L}}+R_{\mathrm{K}}\right) / s C_{\mathrm{o}}}{R_{\mathrm{L}}+R_{\mathrm{K}}+1 / s C_{\mathrm{o}}}} \\
& \times \frac{R_{\mathrm{K}}}{R_{\mathrm{L}}+R_{\mathrm{K}}}=\frac{1}{\frac{L R C_{\mathrm{o}}}{R_{\mathrm{K}}} s^{2}+\frac{R R_{\mathrm{s}} C_{\mathrm{o}}+L}{R_{\mathrm{K}}} s+\frac{R_{\mathrm{s}}+R}{R_{\mathrm{K}}}}
\end{aligned}
$$

In the equation, $R=R_{\mathrm{L}}+R_{\mathrm{K}}, L=L_{\mathrm{s}}+L_{\mathrm{o}}$. Because, 


$$
\Delta=\left(\frac{R R_{\mathrm{s}} C_{\mathrm{o}}+L}{R_{\mathrm{K}}}\right)^{2}-4 \frac{L R C_{\mathrm{o}}}{R_{\mathrm{K}}} \times \frac{R_{\mathrm{s}}+R}{R_{\mathrm{K}}}=3 \times 10^{-10}>0
$$

So, the equivalent circuit is a RLC overdamped circuit. And the process of time response won't occur oscillation.

When $S_{2}$ is closed, suppose that the load resistance becomes to $0.1 \Omega$ at the moment. And before $S$ being closed, The transfer function is still equation (10). The characteristic equation of equation (10) is,

$$
\frac{L R C_{\mathrm{o}}}{R_{\mathrm{K}}} s^{2}+\frac{R R_{\mathrm{s}} C_{\mathrm{o}}+L}{R_{\mathrm{K}}} s+\frac{R_{\mathrm{s}}+R}{R_{\mathrm{K}}}=0
$$

Solve the equation, and get two characteristic roots,

$$
s_{1}=-25000, s_{2}=-3.4 \times 10^{7}
$$

Because $s_{1}$ is near the point of origin, and $s_{1}>4 s_{2}$. So, $s_{1}$ is the predominant pole. The system could be equal to a $\mathrm{RC}$ first order circuit. The voltage of the load is,

$$
U_{0}(t)=U_{\mathrm{i}}(t)\left(1-\mathrm{e}^{-s_{1} t}\right)
$$

The current through the load is,

$$
I_{1}(t)=U_{0}(t) / R_{\mathrm{K}}=U_{\mathrm{i}}(t)\left(1-\mathrm{e}^{-s_{1} t}\right) / R_{\mathrm{K}}
$$

Solve the equation, and get that $t_{2}-t_{1}=0.8 \mu \mathrm{s}, I_{0}=68.4 \mathrm{~A}, I_{s}$ $=85 \mathrm{~A}$.

At the moment, $S$ is triggered. After $5 \mu$ s delay, $S$ is closed completely. $I_{h}=172 \mathrm{~A}$.

Later, the distribution capacitance discharges to the load.
The voltage of the load is,

$$
U_{0}(t)=U_{\mathrm{C}}(t) \mathrm{e}^{-\frac{1}{\tau} t}
$$

The current through the load is,

$$
I_{2}(t)=U_{0}(t) / R_{\mathrm{K}}=U_{\mathrm{C}}(t) \mathrm{e}^{-\frac{1}{\tau} t} / R_{\mathrm{K}}
$$

In the equation, $\tau=R C=9.3 \mu \mathrm{s}$.

After $T=5 \tau=46.5 \mu \mathrm{s}$, the discharge is over. $I$ becomes to zero. The energy injecting into the load is,

$$
Q=\int_{0}^{t} I^{2} R_{\mathrm{K}} \mathrm{d} t=\int_{0}^{5.8} I_{1}^{2} 0.1 \mathrm{~d} t+\int_{5.8}^{52.3} I_{2}^{2} 0.1 \mathrm{~d} t=0.1642 J
$$

\subsection{The Simulation Analysis}

As shown in Figure6., a simulation circuit model has been built by the circuit analysis software of Ansoft Simplorer 7.0. The simulation waveform is shown in Figure6. The power supply and load are protected immediately when the klystron occurs short circuit fault. The voltage $\left(U_{K}\right)$ of the load drops to zero rapidly. The current $\left(I_{K}\right)$ through the load increases from $68 \mathrm{~A}$ to the peak value $170 \mathrm{~A}$. Then it discharges to zero gradually. The simulation circuit is an ideal model. So, there is no delay for all switches. In addition to this point, the simulation waveform is largely in line with the analytic calculation. And by the integral calculation for the subtriangular area of simulation waveform, the energy of injecting into the load is about,

$$
Q=\int{ }_{0}^{t} I^{2} R_{K} d t \approx 170^{2} * 0.1 * 60 * 10^{-6} J=0.1734 J
$$

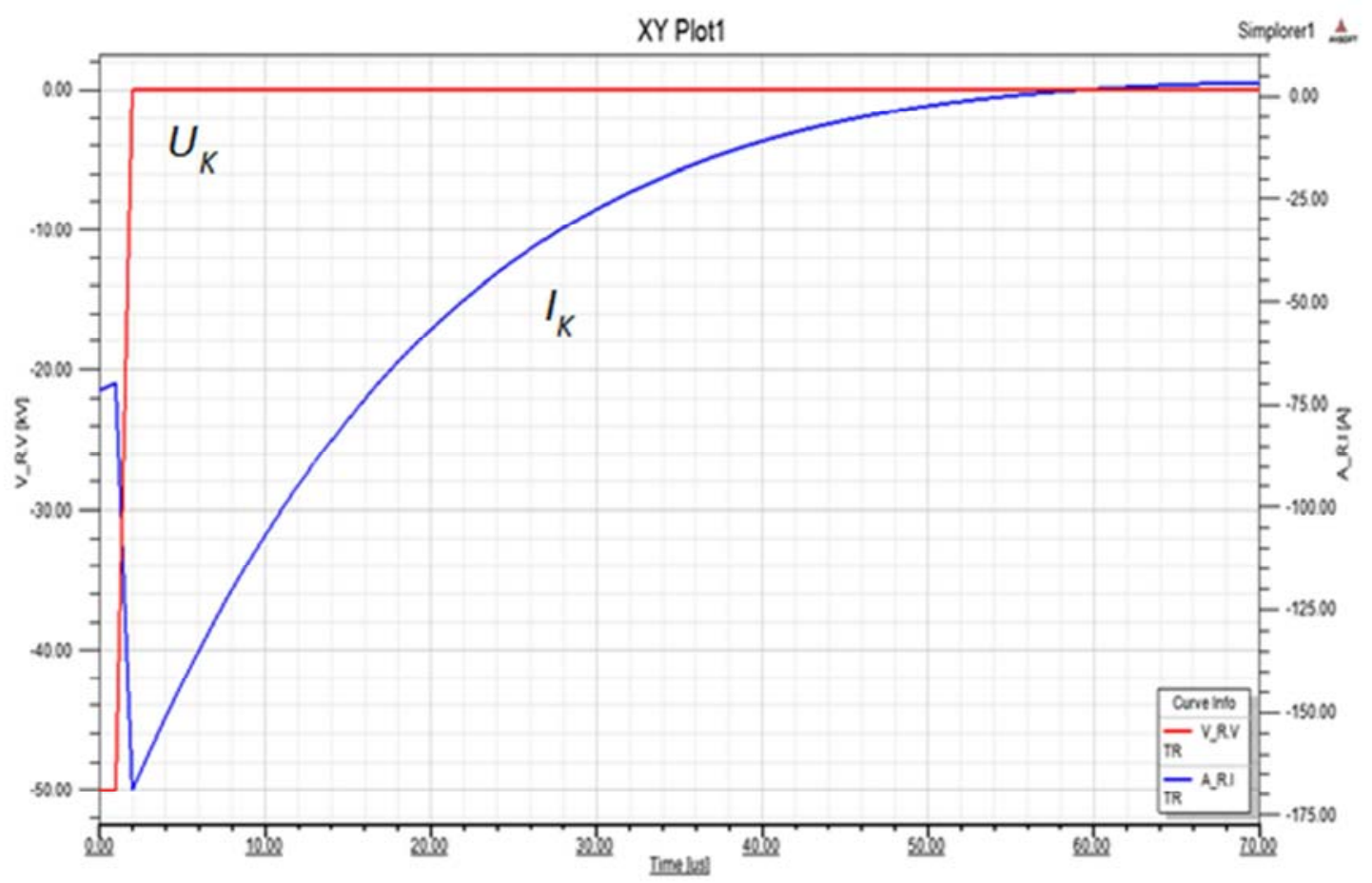

Figure 6. The simulation waveform of short circuit fault transient process. 


\section{Experimental Result}

A experimental platform has been built for the experiment of short circuit fault. HVPS is running at full power. The klystron is instead of the dummy load. The current setting of protection switch trigger is $85 \mathrm{~A}$. Control signal is transmitted through the fiber-optic network. The voltage signal and current signal of the load are collected by an oscilloscope, whose type is Tektronix TPS2024. And the experimental waveform is shown in Figure 7. When the load occurs the short circuit fault, the current is increasing rapidly. About $5 \mu \mathrm{s}$ later, the three-electrode gas switch is triggered. HVPS and the load are protected. Then the current begins to decrease, and it decreases to zero gradually after $50 \mu \mathrm{s}$. Ignore the noise of signal. Stick out the envelope line of signal. The max current is about 200A. Finally, by the integral calculation for the subtriangular area of experimental waveform, the energy of injecting into the load is $\mathrm{Q} \approx 0.24 \mathrm{~J}$. The result is approximate with the analytic calculation and the simulation value. And 4.6GHz/6MW LHCD system is successfully used in 2015 EAST campaign. As shown in Figure 8., it is the typical experimental waveform at No.57115 shot in 2015 EAST campaign. It is obvious that $\mathrm{H}$-mode plasma can be obtained with LHCD $(2.45 \mathrm{GHz}$ and $4.6 \mathrm{GHz})$ at high density. Which is indirectly demonstrated that HVPS has good performance for 4.6GHz/6MW LHCD system in EAST.

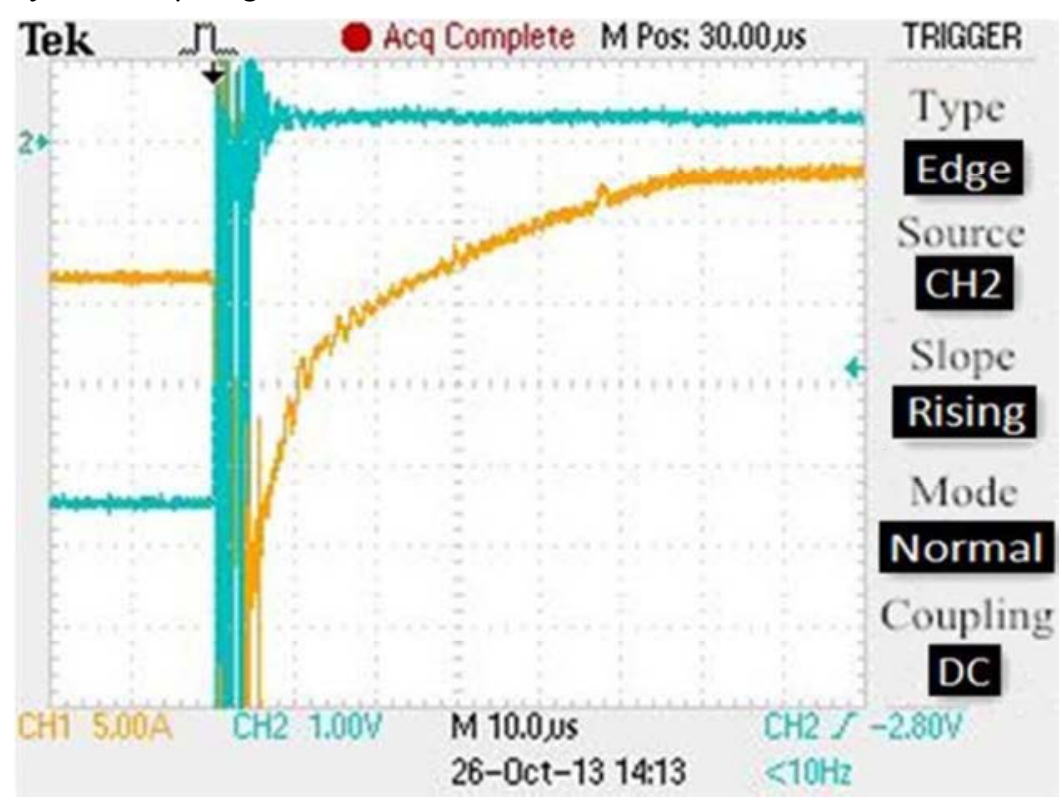

Figure 7. The experimental waveform of short circuit fault transient process.

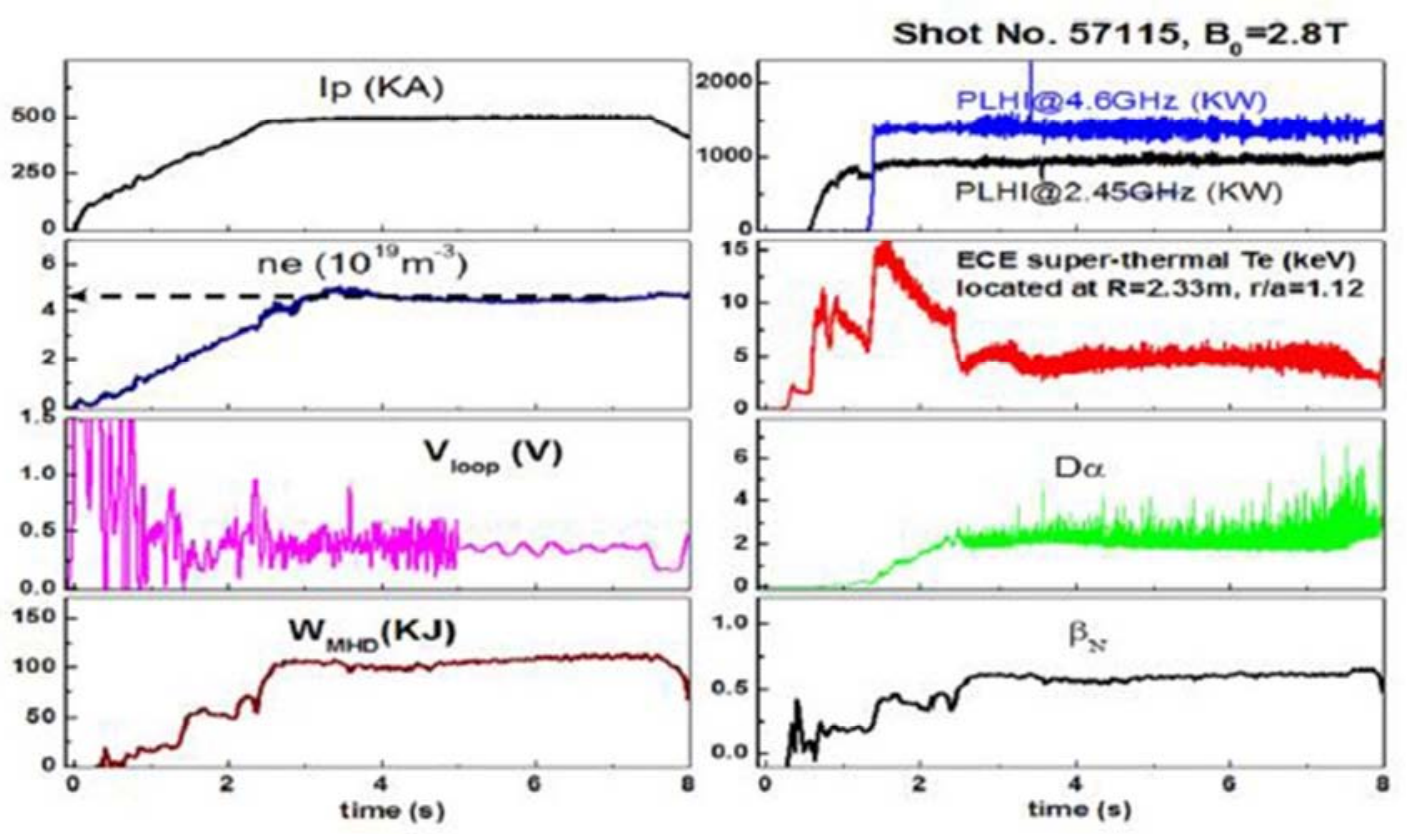

Figure 8. The typical experimental waveform at No.57115 shot in 2015 EAST campaign. 


\section{Conclusion}

A high voltage power supply based on PSM switching technology is introduced in this paper, which is supplying power for the $4.6 \mathrm{GHz} / 6 \mathrm{MW} \mathrm{LHCD}$ in EAST. The distribution capacitance and stray inductance of the transmission cables are quantitatively analyzed. And the transient process of short-circuit fault is detailed calculated by the methods of the analytic calculation and simulation. Experimental result is almost consistent with the analytic calculation and simulation. And the energy of injecting into the load is $\mathrm{Q} \approx 0.24 \mathrm{~J}$, which is much less than $10 \mathrm{~J}$. So it suggests that the power supply and its load are immediately protected well by the three-electrode gas switch, when the klystron occurs short circuit fault. Then HVPS works well and meets the requirement for $4.6 \mathrm{GHz} / 6 \mathrm{MW}$ LHCD system in the entire 2015 EAST campaign.

\section{References}

[1] Y. X. Wan, P. D. Weng, J. G. Li, D. M. Gao, S. T. Wu, and EAST Team. In Progress of the EAST Project in China [C]. 21th International Atomic Energy Agency (IAEA) Fusion Energy Conference, 2004, FT/3-3: 1-8.

[2] Chengyao Peng, Jiafang Shan, et al.. Design of temperature compensating unit for the circulator in $6 \mathrm{MW} 4.6 \mathrm{GHz}$ LHCD system [J]. Fusion Engineering and Design, 2016, (112): 198-203.

[3] J. Hillairet, J. Kim, N. Faure, et al.. Design and tests of $500 \mathrm{~kW}$ RF windows for the ITER LHCD system [J]. Fusion Engineering and Design, 2015, (94): 22-30.

[4] Francesco Mirizzi. Prolegomena to the RAMI analysis of a conceptual LHCD system for DEMO [J]. Fusion Engineering and Design, 2013, (88): 887-890.
[5] Jun Li, Fukun Liu. Electromagnetic disruption analysis of 2.45 $\mathrm{GHz}$ LHW antenna in EAST under different plasma configurations [J]. Fusion Engineering and Design, 2011 (86): 214-219.

[6] Zhigang Yang, Peng Fu, et al.. Analysis of anti-short circuit strength on windings for ITER-PPEN power transformer [J]. Fusion Engineering and Design, 2017, (121): 108-113.

[7] Yiyun. Huang. Reconstruction of $-35 \mathrm{kV} / 200 \mathrm{~kW}$ HVPS for test of klystron units in LHCD system [J]. Plasma Science and Technology, 2004, (6): 2224-2227.

[8] Yiyun. Huang. Design and experimental results of feedback control of Ohmic-heating transformer magnetic flux by LHCD power in HT-7 Tokamak [J]. Fusion Engineering and Design , 2006, (81): 2085-2091.

[9] Xu Hao, Yi Yun Huang. The design of high voltage DC power supply of $4.6 \mathrm{GHz} / 500 \mathrm{MW}$ LHCD [J]. Applied Mechanics and Materials [J]. 2011, (135): 1027-1036.

[10] Srinivas YSS, Kushwah M, Kulkarni SV, et al.. Results of 10-Joule wire-burn test performed on $70 \mathrm{kV}$ rail-gap crowbar protection system for high power klystrons and gyrotron [C]. 19th Symposium on Fusion Engineering, 2002: 91-94.

[11] Y. Y. Huang, B. H. Liu, W. H. Xu, G. L. Kuang. The Pulse High voltage Power Supply with Star point Modulator and the Mathematics Analysis Simulation [J]. High Voltage Engineering, 2000, (26): 28-30.

[12] William H. Hayt, Jr et al.. engineering electromagnetics (Seventh Edition) [M]. The McGraw-Hill Companies, Inc., 2006.

[13] A. Budak. Circuit theory fundamentals and applications [M]. Prentice-Hall, Inc., 1978. 